УДК 621.822 .05

\title{
С.I. Задерієнко
}

Академія сухопутних військ імені гетьмана Петра Сагайдачного

\section{МАТЕМАТИЧНЕ МОДЕЛЮВАННЯ ГІДРОДИНАМІЧНОГО МАЩЕННЯ ЗБІРНОГО КОНІЧНОГО ПІДШИПНИКА 3 ПОРИСТИМ ШАРОМ НА ЙОГО РОБОЧІЙ ПОВЕРХНІ}

У роботі на основі нестаціонарних нелінійних рівнянь Навьє-Стокса для випадку «тонкого шару» $i$ рівняння Дарсі з використанням принцииу конструктивної суперпозиції розроблений метод гідродинамічного розрахунку збірного конічного підшипника опорних вузлів озброєння $і$ військової техніки. Дана оцінка впливу кута конусності і протяжності пористої складової на основні робочої характеристики підиипника.

Ключові слова: озброєння і військова техніка, гідродинамічне мащення, збірний підиипник, пористий шар.

\section{Вступ}

Аналіз останніх досліджень і публікацій. Як відомо, конічні підшипники рідинного тертя широко застосовуються як в навантажених вузлах озброєння i військової техніки, так i як конструктивний елемент опорних вузлів високошвидкісних роторних машин. Застосування конічних радіально-натискних підшипників у вузлах високошвидкісних опорних машин дозволяє зменшити габаритні розміри опор, понизити енергетичні втрати, поліпшити динамічні характеристики опорних вузлів [1,2]. Тому математичне моделювання гідродинамічного мащення поверхонь тертя, зокрема розробка методу гідродинамічного розрахунку конічних підшипників, представляє теоретичний і практичний інтерес. Аналіз публікацій у даній області показує, що в роботах, присвячених розрахунку конічних підшипників, розглядаються або суцільні конічні підшипники [1], або ті, що містять пористий шар на всій робочій поверхні [3]. У даній роботі приводиться метод гідродинамічного розрахунку збірного конічного підшипника, що працює в нестаціонарному режимі.

Постановка завдання. Розглядається несталий рух в’язкої нестискуваної рідини в зазорі збірного конічного підшипника кінцевої довжини. Вкладиш, що $\epsilon$ сукупністю суцільних і пористих втулок, запресованих у непроникний конічний корпус, визнається нерухомим, а конічна шпилька обертається $з$ постійною кутовою швидкістю $\omega$, на яку накладаються коливання $\Omega^{\prime}\left(t^{\prime}\right)$. Також передбачається, що олива подається в осьовому напрямі і в двох торцевих перетинах із заданим тиском. Помістимо початок циліндрової системи $r^{\prime}, \theta, z^{\prime}$ у лівому кінці на осі підшипника (рис. 1), вісь $z$ направимо по осі підшипника. У вибраній системі координат рівняння контурів $c_{2}, c_{1}$ i $c_{0}$, записуються у вигляді:

$$
\mid \begin{aligned}
& r^{\prime}=r_{2}+z^{\prime} \operatorname{tg} \alpha \\
& r^{\prime}=r_{1}+z^{\prime} \operatorname{tg} \alpha \\
& r^{\prime}=r_{0}+z^{\prime} \operatorname{tg} \alpha+e \cos \theta
\end{aligned}
$$

де $r_{0}$-радіус шпильки; $r_{1}$-радіус вкладиша в перетині $z^{\prime}=0 ; \delta=\left(r_{2}-r_{1}\right) \cos \alpha-$ товщина пористого шару; $e$ - ексцентриситет; $\alpha$ - кут конусності підшипника.

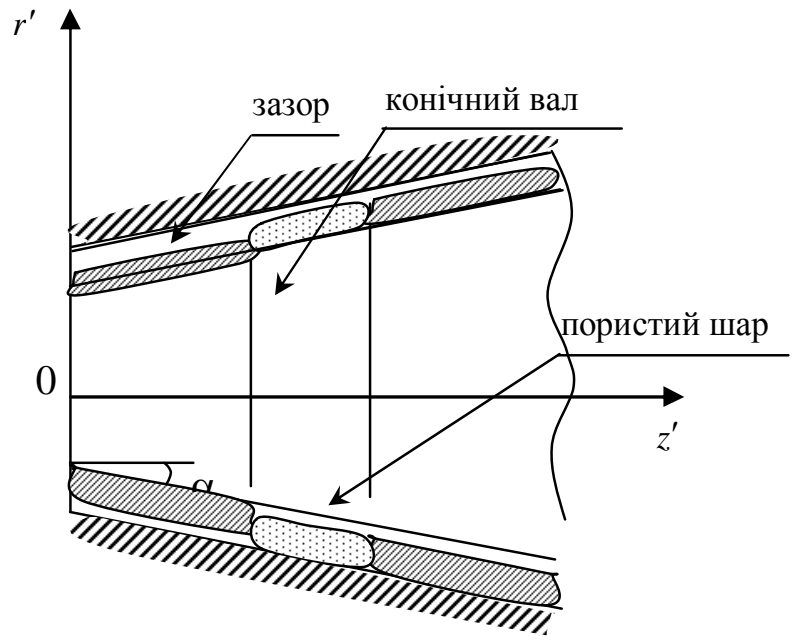

Рис. 1. Схематичне зображення збірного конічного підшипника

\section{Основна частина}

При визначенні граничних умов виходитимемо 3 нелінійних нестаціонарних рівнянь Навьє-Стокса для «тонкого шару» [3], рівняння нерозривності i рівняння Дарсі: 


$$
\begin{aligned}
& \frac{\partial v_{r}}{\partial t^{\prime}}=v_{r} \frac{\partial v_{r}}{\partial r}+\frac{v_{\theta}}{r} \frac{\partial v_{\theta}}{\partial \theta}+v_{z} \frac{\partial v_{r}}{\partial z}-\frac{v_{\theta}^{2}}{r}=-\frac{1}{\rho} \frac{\partial p}{\partial r}+ \\
& +v\left(\frac{\partial^{2} v_{r}}{\partial r^{2}}+\frac{1}{r^{2}} \frac{\partial^{2} v_{r}}{\partial \theta^{2}}+\frac{\partial^{2} v_{r}}{\partial z^{2}}+\frac{1}{r} \frac{\partial v_{r}}{\partial r}-\frac{2}{r^{2}} \frac{\partial v_{\theta}}{\partial \theta}-\frac{v_{r}}{r^{2}}\right) \\
& \frac{\partial v_{\theta}}{\partial t^{\prime}}=v_{r} \frac{\partial v_{\theta}}{\partial r}+\frac{v_{\theta}}{r} \frac{\partial v_{\theta}}{\partial \theta}+v_{z} \frac{\partial v_{\theta}}{\partial z}+\frac{v_{r} v_{\theta}}{r}=-\frac{1}{\rho r} \frac{\partial p}{\partial \theta}+ \\
& +v\left(\frac{\partial^{2} v_{\theta}}{\partial r^{2}}+\frac{1}{r^{2}} \frac{\partial^{2} v_{\theta}}{\partial \theta^{2}}+\frac{\partial^{2} v_{\theta}}{\partial z^{2}}+\frac{1}{r} \frac{\partial v_{\theta}}{\partial r}+\frac{2}{r^{2}} \frac{\partial v_{r}}{\partial \theta}-\frac{v_{\theta}}{r^{2}}\right) \\
& \frac{\partial v_{z}}{\partial t^{\prime}}=v_{r} \frac{\partial v_{z}}{\partial r}+\frac{v_{\theta}}{r} \frac{\partial v_{z}}{\partial \theta}+v_{z} \frac{\partial v_{z}}{\partial z}=-\frac{1}{\rho} \frac{\partial p}{\partial z}+ \\
& +v\left(\frac{\partial^{2} v_{z}}{\partial r^{2}}+\frac{1}{r^{2}} \frac{\partial^{2} v_{z}}{\partial \theta^{2}}+\frac{\partial^{2} v_{z}}{\partial z^{2}}+\frac{1}{r} \frac{\partial v_{z}}{\partial r}\right) ; \\
& \frac{\partial v_{r}}{\partial r}+\frac{1}{r} \frac{\partial v_{\theta}}{\partial \theta}+\frac{\partial v_{z}}{\partial z}+\frac{v_{r}}{r}=0
\end{aligned}
$$

Система рівнянь (2) вирішується за наступних граничних умов:

прилипання оливи до поверхні шпильки i підшипника;

на внутрішній поверхні вкладиша (при $z \in\left(z_{1}, z_{2}\right)$ ) нормальна складова швидкості визначається законом Дарсі;

під час переходу через пористу межу $\left(z \in\left(z_{1}, z_{2}\right)\right)$ тиск міняється безперервно;

на зовнішній поверхні пористого шару нормальна складова швидкості дорівнює нулю;

у двох перетинах (у початковому і кінцевому) тиск заданий. Приведемо початкові умови:

$$
\begin{gathered}
\left.p^{\prime}\right|_{t^{\prime}=0}=p^{(0)},\left.v_{r}\right|_{t^{\prime}=0}=v_{r}^{(0)},\left.v_{\theta}\right|_{t^{\prime}=0}=v_{\theta}^{(0)}, \\
\left.v_{z}\right|_{t^{\prime}=0}=v_{z}^{(0)},\left.P^{\prime}\right|_{t^{\prime}=0}=P^{(0)} .
\end{gathered}
$$

Тут $\quad p^{(0)}, v_{r}^{(0)}, v_{\theta}^{(0)}, v_{z}^{(0)}, P^{\prime(0)} \quad-\quad$ рішення відповідної стаціонарної задачі.

Для вирішення поставленого завдання використовується прийом конструктивної суперпозиції, що полягає в наступному: спочатку послідовно вирішуються дві задачі, пов'язані 3 розробкою методу розрахунку збірних циліндрових підшипників 3 конструктивними параметрами, відповідними перетинам $z^{\prime}=0 \quad$ i $\quad z^{\prime}=l$ збірного конічного підшипника. У подальшому визначається лінійна суперпозиція цих рішень.

Задача 1. Розробка методу розрахунку збірного циліндрового підшипника 3 радіусом шпильки $r_{0}$, вкладиша $r_{1}$ i 3 товщиною пористої втулки, що становить $\delta$ Визначення поля швидкостей $\mathrm{v}_{r}^{(1)}$, $v_{\theta}^{(1)}, v_{z}^{(1)}$ і тиску відповідно в змащувальному шарі $p^{\prime(1)}$ і в пористому $P^{\prime(1)}$.
Задача 2. Розрахунок збірного циліндрового підшипника 3 радіусом шпильки $r_{0}+l \operatorname{tg} \alpha$ і вкладиша $r_{1}+l \operatorname{tg} \alpha$. Визначення поля швидкостей $v_{r}^{(2)}, v_{\theta}^{(2)}, v_{z}^{(2)}$ і полів тиску $\quad p^{(1)} \grave{e} P^{\prime(2)}$ i $p^{\prime(1)} \grave{e} P^{\prime(2)} .3$ використанням рішень задачі $1 \mathrm{i}$ задачі 2 наближене рішення даного завдання представляється у вигляді лінійної суперпозиції цих рішень, тобто [4]:

$$
\begin{gathered}
p^{\prime}=p^{(1)} \theta^{*}+p^{(2)}\left(1-\theta^{*}\right), v_{r}=v_{r}^{(1)} \theta^{*}+v_{r}^{(2)}\left(1-\theta^{*}\right), \\
v_{\theta}=v_{\theta}^{(1)} \theta^{*}+v_{\theta}^{(2)}\left(1-\theta^{*}\right), v_{z}=v_{z}^{(1)} \theta^{*}+v_{z}^{(2)}\left(1-\theta^{*}\right), \\
P^{\prime}=P^{\prime(1)} \theta^{*}+P^{(2)}\left(1-\theta^{*}\right), \theta^{*} \in[0,1] .
\end{gathered}
$$

Знайдемо рішення задачі 1 . Перейдемо в змащувальному шарі до безрозмірних змінних за формулами

$$
\begin{gathered}
v_{r^{\prime}}^{(1)}=\omega \delta u^{(1)}, v_{\theta}^{(1)}=\omega r_{0} \mathrm{v}^{(1)}, \\
v_{z^{\prime}}^{(1)}=\omega r_{0} w^{(1)}, p^{\prime(1)}=p^{*} p^{(1)}, \\
r^{\prime}=r_{1}-\delta r, z^{\prime}=r_{0} z, \delta=r_{1}-r_{0}, \\
p^{*}=\frac{\mu \omega r_{0}^{2}}{\delta^{2}}, t^{\prime}=t^{*} t, t^{*}=\frac{\rho \delta^{2}}{\mu} .
\end{gathered}
$$

$\mathrm{y}$ пористому шарі перехід до безрозмірних змінних здійснимо за формулами

$$
\begin{array}{cc}
r^{\prime}=\tilde{\delta} \tilde{\xi}, & P^{\prime}=p^{*} P^{(1)}, P^{(1)}=p^{*} P^{(1)}, \\
z^{\prime}=r_{0} z, \quad \tilde{\delta}=r_{2}-r_{1} .
\end{array}
$$

Використовуючи (5) і (6), систему рівнянь (2) і граничні умови (3) у разі даного циліндрового підшипника 3 пористим шаром на робочій поверхні, можна записати рішення задачі у вигляді (3 точністю до членів $O\left(\frac{\delta}{r_{1}}\right), O\left(\frac{\tilde{\delta}^{2}}{r_{0}^{2}}\right)$ ):

$$
\begin{gathered}
\frac{\partial P^{(1)}}{\partial r}=0,-\frac{\partial v^{(1)}}{\partial t}+\frac{\partial^{2} v^{(1)}}{\partial r^{2}}=\frac{\partial P}{\partial \theta}+\operatorname{Re}\left(u^{(1)} \frac{\partial v^{(1)}}{\partial r}+\right. \\
\left.+v^{(1)} \frac{\partial v^{(1)}}{\partial \theta}+w^{(1)} \frac{\partial v^{(1)}}{\partial z}\right), \\
-\frac{\partial w^{(1)}}{\partial t}+\frac{\partial^{2} w^{(1)}}{\partial r^{2}}=\frac{\partial P}{\partial z}+\operatorname{Re}\left(u^{(1)} \frac{\partial w^{(1)}}{\partial r}+\right. \\
\left.+v^{(1)} \frac{\partial w^{(1)}}{\partial \theta}+w^{(1)} \frac{\partial w^{(1)}}{\partial z}\right), \\
\frac{\partial u^{(1)}}{\partial r}+\frac{\partial v^{(1)}}{\partial \theta}+\frac{\partial^{2} w^{(1)}}{\partial z}=0, B^{*} \frac{\partial P^{(1)}}{\partial t}=\frac{\partial^{2} P^{(1)}}{\partial \tilde{\xi}^{2}}+ \\
+\frac{1}{\tilde{\xi}} \frac{\partial P^{(1)}}{\partial \tilde{\xi}}+\frac{1}{\xi^{2}} \frac{\partial^{2} P^{(1)}}{\partial \theta^{2}}+\frac{\partial^{2} P^{(1)}}{\partial z^{2}}=0 . \\
u_{r=0}^{(1)}=-\left.\left.N^{(1)} \frac{\partial P}{\partial \tilde{\xi}}\right|_{\tilde{\xi}=\frac{r_{1}}{\tilde{\delta}}, v^{(1)}}\right|_{r=0}=0,\left.w\right|_{r=0}=0,
\end{gathered}
$$




$$
\begin{aligned}
& p=\left.P\right|_{\tilde{\xi}=\frac{r_{1}}{\tilde{\delta}}}, \quad N^{(1)}=\frac{k r_{0}^{2}}{\delta^{3} \widetilde{\delta}}, \\
& \left.u^{(1)}\right|_{r=1-\eta \cos \theta}=-\eta \sin \theta-\frac{\Omega^{\prime} \eta \sin \theta}{\omega}, \eta=\frac{e}{\delta}, \\
& \left.v^{(1)}\right|_{r=1-\eta \cos \theta}=1+\frac{\Omega^{\prime}}{\omega},\left.w^{(1)}\right|_{r=1-\eta \cos \theta}=0, \\
& \left.p^{(1)}\right|_{z=0}=\varphi_{1}(\theta, t) / p^{*},\left.p^{(1)}\right|_{z=\gamma=\frac{l}{r_{0}}}=\varphi_{2}(\theta, t) / p^{*}, \\
& \left.\frac{\partial P^{(1)}}{\partial \tilde{\xi}}\right|_{\tilde{\xi}=\frac{r_{2}}{\widetilde{\delta}}}=0, N^{(1)}=0 \quad n p u \quad z \in\left(\frac{z_{1}}{r_{0}}, \frac{z_{2}}{r_{0}}\right), \\
& B^{*(1)}=\frac{B \tilde{\delta}^{2}}{t^{*}}, \operatorname{Re}=\frac{\rho \omega \delta^{2}}{\mu}, \\
& \left.p^{(1)}\right|_{t=0}=p^{(0)},\left.u^{(1)}\right|_{t=0}=u^{(0)},\left.v^{(1)}\right|_{t=0}=v^{(0)} \text {, } \\
& \left.w\right|_{t=0}=w^{0},\left.P^{(1)}\right|_{t=0}=P^{(0)} .
\end{aligned}
$$

Тут $p^{(0)}, u^{(0)}, v^{(0)}, w^{(0)}, P^{(0)}-$ рішення відповідної безрозмірної стаціонарної задачі.

У системі рівнянь (7) усереднимо по товщині змащувального шару члени, обумовлені силою інерції, а також усереднимо рівняння Дарсі по товщині пористого шару. Введемо наступні позначення:

$$
\begin{aligned}
& M_{1}^{(1)}=\frac{1}{1-\eta \cos \theta} \int_{0}^{1-\eta \cos \theta}\left[\frac{\partial v^{(1)}}{\partial t}+\operatorname{Re}\left(u^{(1)} \frac{\partial v^{(1)}}{\partial r}+\right.\right. \\
& \left.\left.+v^{(1)} \frac{\partial v^{(1)}}{\partial \theta}+w^{(1)} \frac{\partial v^{(1)}}{\partial z}\right)\right] d r, \\
& M_{2}^{(1)}=\frac{1}{1-\eta \cos \theta} \int_{0}^{1-\eta \cos \theta}\left[\frac{\partial w^{(1)}}{\partial t}+\operatorname{Re}\left(u^{(1)} \frac{\partial w^{(1)}}{\partial r}+\right.\right. \\
& \left.\left.+v^{(1)} \frac{\partial w^{(1)}}{\partial \theta}+w^{(1)} \frac{\partial w^{(1)}}{\partial z}\right)\right] d r, \\
& \int_{\frac{r_{1}}{\widetilde{\delta}}}^{\frac{r_{2}}{\widetilde{\delta}}} B^{*} \frac{\partial P^{(1)}}{\partial t} d r=\int_{\frac{r_{1}}{\widetilde{\delta}}}^{\frac{r_{2}}{\widetilde{\delta}}}\left(\frac{\partial^{2} P^{(1)}}{\partial \tilde{\xi}^{2}}+\frac{1}{\tilde{\xi}} \frac{\partial P^{(1)}}{\partial \tilde{\xi}}+\right. \\
& \left.+\frac{1}{\xi^{2}} \frac{\partial^{2} P^{(1)}}{\partial \theta^{2}}\right) d r .
\end{aligned}
$$

Точне автомодельне рішення задачі (7) - (8) 3 урахуванням (9) шукатимемо у вигляді:

$$
\begin{gathered}
u^{(1)}=-\frac{\partial \psi^{(1)}}{\partial \theta}+U^{(1)}(r, \theta, t), v^{(1)}=\frac{\partial \psi^{(1)}}{\partial r}+V^{(1)}(r, \theta, t), \\
w^{(1)}=\widetilde{w}(\xi, t), U^{(1)}=\widetilde{u}^{(1)}(\xi, t) h^{\prime}(\theta), \\
V^{(1)}=\widetilde{v}^{(1)}(\xi, t),
\end{gathered}
$$

$$
\begin{gathered}
\xi=\frac{r}{h(\theta)}, \psi^{(1)}=\tilde{\psi}^{(1)}(\xi, t), p^{(1)}+\int_{0}^{\theta} M_{1}^{(1)}(\theta, t) d \theta= \\
=\int_{0}^{\theta}\left(\frac{\tilde{c}_{1}(t)}{h^{2}}+\frac{\tilde{c}_{2}(t)}{h^{3}}\right) d \theta+a z+b, \\
P^{(1)}=A^{(1)}(\theta, t)\left(\tilde{\xi}-\frac{r_{1}}{\delta}\right)\left(\tilde{\xi}-\frac{r_{2}}{\delta}\right)^{2}+ \\
+A^{*(1)}(t)\left(\tilde{\xi}-\frac{r_{1}}{\delta}\right)\left(1-\frac{1}{2}\left(\tilde{\xi}-\frac{r_{1}}{\tilde{\delta}}\right)\right) \eta \sin \theta .(10)
\end{gathered}
$$

Підставивши (10) в (7) і (8) з урахуванням (9), матимемо:

$$
\begin{aligned}
& \frac{\partial^{3} \tilde{\psi}^{(1)}}{\partial \xi^{3}}=\tilde{c}_{2}(t), \frac{\partial^{2} \tilde{v}^{(1)}}{\partial \xi^{2}}=\tilde{c}_{1}(t), \\
& \frac{\partial^{2} w^{(1)}}{\partial \xi^{2}}=a h^{2}(\theta)+M_{2}^{(1)} h^{2}(\theta), \\
& \frac{\partial \tilde{u}^{(1)}}{\partial \xi}-\xi \frac{\partial \tilde{v}^{(1)}}{\partial \xi}=0, \\
& B^{*(1)} \beta_{4} \frac{\partial A^{*(1)}}{\partial t}=A^{*(1)}\left(-\beta_{4}+\beta_{5}+\beta_{6}\right), \\
& B^{*(1)} \beta_{4} \frac{\partial A^{(1)}}{\partial t}=\beta_{3} \frac{\partial^{2} A^{(1)}}{\partial \theta^{2}}+A^{(1)}\left(\beta_{1}+\beta_{2}\right)+\frac{\partial^{2} p^{(1)}}{\partial \theta^{2}} \text {. } \\
& \frac{\partial \tilde{\psi}^{(1)}}{\partial \xi}(\theta, t)=\frac{\partial \tilde{\psi}^{(1)}}{\partial \xi}(1, t)=0, \tilde{u}^{(1)}(\theta, t)=-N A^{*(1)}, \\
& v^{(1)}(0, t)=0, \tilde{w}^{(1)}(0, t)=0, \tilde{u}^{(1)}(1, t)=1-\frac{\Omega^{\prime}}{\omega}, \\
& \widetilde{v}^{(1)}(1, t)=-1+\frac{\Omega^{\prime}}{\omega}, \tilde{w}^{(1)}(1, t)=0, \\
& p^{(1)}=\left.P^{(1)}\right|_{\tilde{\xi}=\frac{r_{1}}{\tilde{\delta}}},\left.\frac{\partial P^{(1)}}{\partial \tilde{\xi}}\right|_{\tilde{\xi}=\frac{r_{2}}{\tilde{\delta}}}=0, \\
& A^{(1)}(0, t)=A^{(1)}(2 \pi, t) \text {; } \\
& p^{(1)}(0, z, t)=p^{(1)}(2 \pi, z, t) . \\
& \text { Тут } \beta_{1}=\int_{\frac{r_{1}}{\tilde{\delta}}}^{\frac{r_{2}}{\tilde{\delta}}} \frac{d^{2}}{d \tilde{\xi}^{2}}\left[\left(\tilde{\xi}-\frac{r_{1}}{\tilde{\delta}}\right)\left(\tilde{\xi}-\frac{r_{2}}{\tilde{\delta}}\right)^{2}\right] d \tilde{\xi}, \\
& \beta_{2}=\int_{\frac{r_{1}}{\tilde{\delta}}}^{\frac{r_{2}}{\tilde{\delta}}} \frac{1}{\tilde{\xi}} \frac{d}{d \xi}\left[\left(\tilde{\xi}-\frac{r_{1}}{\delta}\right)\left(\tilde{\xi}-\frac{r_{2}}{\tilde{\delta}}\right)^{2}\right] d \tilde{\xi} ; \\
& \beta_{3}=\int_{\frac{r_{1}}{\delta}}^{\frac{r_{2}}{\tilde{\delta}}}\left(\tilde{\xi}-\frac{r_{1}}{\delta}\right)\left(\tilde{\xi}-\frac{r_{2}}{\delta}\right)^{2} d \tilde{\xi},
\end{aligned}
$$




$$
\begin{gathered}
\beta_{4}=\int_{\frac{n_{1}}{\tilde{\delta}}}^{\frac{r_{2}}{\widetilde{\delta}}}\left(\tilde{\xi}-\frac{r_{1}}{\delta}\right)\left(1-\frac{1}{2}\left(\tilde{\xi}-\frac{r_{1}}{\delta}\right)\right) d \tilde{\xi} ; \\
\beta_{5}=\int_{\frac{r_{1}}{\tilde{\delta}}}^{\frac{r_{2}}{\delta}} \frac{d^{2}}{d \xi^{2}}\left[\left(\tilde{\xi}-\frac{r_{1}}{\tilde{\delta}}\right)\left(1-\frac{1}{2}\left(\tilde{\xi}-\frac{r_{1}}{\delta}\right)\right)\right] d \tilde{\xi}, \\
\beta_{6}=\int_{\frac{r_{1}}{\tilde{\delta}}}^{\frac{r_{2}}{\delta}} \frac{d}{\tilde{\xi}} \frac{d}{d \xi}\left[\left(\tilde{\xi}-\frac{r_{1}}{\tilde{\delta}}\right)\left(1-\frac{1}{2}\left(\tilde{\xi}-\frac{r_{1}}{\tilde{\delta}}\right)\right)\right] d \xi .
\end{gathered}
$$

Рішення задачі (11) - (12) знаходиться безпосередньою інтеграцією. В результаті матимемо:

$$
\begin{aligned}
& \frac{\partial \tilde{\psi}^{(1)}}{\partial \xi}=\frac{\tilde{c}_{2}}{2}\left(\xi^{2}-\xi\right), \tilde{u}^{(1)}=\int_{0}^{\xi} \xi \frac{\partial \tilde{v}^{(1)}}{\partial \xi} d \xi, \\
& \tilde{v}^{(1)}=\frac{\tilde{c}_{1}}{2} \xi^{2}+\left(1+\frac{\Omega^{\prime}}{\omega}\right) \xi, \\
& \tilde{w}^{(1)}=\frac{a h^{2}}{2}\left(\xi^{2}-\xi\right)+\frac{M_{2}^{(1)} h^{2}}{2}\left(\xi^{2}-\xi\right), \\
& p^{(1)}=\int_{0}^{\theta}\left(\frac{\tilde{c}_{1}(t)}{h^{2}(\theta)}+\frac{\tilde{c}_{2}(t)}{h^{3}(\theta)}\right) d \theta+a z+b-\int_{0}^{\theta} M_{1}^{(1)}(\theta, z) d \theta, \\
& M_{1}^{(1)}(\theta, t)=-\frac{\tilde{c}_{2}{ }^{\prime}}{12 h}-\frac{\tilde{c}_{1}^{\prime}}{6}+\frac{1}{2 \omega} \frac{d \Omega^{\prime}}{d t}+ \\
& +\operatorname{Re} \int_{0}^{1}\left\{( - \frac { \partial \widetilde { \psi } ^ { ( 1 ) } } { \partial \xi } \xi \cdot \frac { h ^ { \prime } ( \theta ) } { h } + \square ^ { ( 1 ) } h ^ { \prime } ( \theta ) ) \left(\frac{1}{h^{2}} \frac{\partial \widetilde{\psi}^{(1)}}{\partial \xi^{2}}+\right.\right. \\
& \left.+\frac{1}{h} \frac{\partial \widetilde{v}^{(1)}}{\partial \xi}\right)+\left(\frac{1}{h} \frac{\partial \widetilde{\psi}^{(1)}}{\partial \xi}+\widetilde{v}^{(1)}\right)\left(-\frac{h^{\prime}}{h^{2}} \frac{\partial \psi^{(1)}}{\partial \xi}-\right. \\
& \left.\left.-\frac{1}{h^{2}} \frac{\partial^{2} \widetilde{\psi}^{(1)}}{\partial \xi^{2}} \xi \cdot \frac{h^{\prime}}{h^{2}}-\frac{\partial \widetilde{v}^{(1)}}{\partial \xi} \xi \frac{h^{\prime}}{h}\right)\right\} \cdot d \xi . \\
& A^{*(1)}(t)=e^{-\frac{\beta_{4}-\beta_{5}-\beta_{6}}{B^{*} \beta_{4}} t} \cdot A_{0}^{*(1)}, \\
& \tilde{c}_{1}^{(1)}=6+18 \frac{\Omega^{\prime}}{\omega}+12 N^{(1)} A^{*(1)}, A_{0}^{*(1)}=\text { const. }
\end{aligned}
$$

Явний вид функції $A^{(1)}(\theta, t) \quad M_{2}^{(1)}(\theta, t)$ при визначенні основних робочих характеристик нам не знадобиться. Дотримуючи періодичність гідродинамічного тиску по $\theta$, для визначення $\square_{2}(t)$ приходимо до наступного рівняння:

$$
\int_{0}^{2 \pi}\left(\frac{\tilde{c}_{1}}{h^{2}}+\frac{\tilde{c}_{2}}{h^{3}}\right) d \theta-\int_{0}^{2 \pi} M_{1}^{(1)}(\theta, t) d \theta=0 .
$$

Таким чином, задача 1 повністю вирішена. Задача 2 вирішується за тією ж схемою. Перехід до безрозмірних змінних здійснюється за формулами
(5) із заміною в даному випадку $r_{0}$ на $r_{0}+l \operatorname{tg} \alpha$ i $r_{1}$ на $\quad r_{1}+\operatorname{ltg} \alpha$. Для $\tilde{\psi}^{(2)}, \tilde{u}^{(2)}, \tilde{v}^{(2)}, w^{(2)}, p^{(2)}$ і $P^{(2)}$ отримаємо вирази, аналогічні (13) і (14).

Перейдемо до визначення дії оливи на підшипник. Для проекцій головного вектора i головного моменту у разі задачі 1 матимемо наступні вирази:

$$
\begin{gathered}
R_{y^{\prime}}^{(1)}=r_{1} r_{0} \frac{\mu \omega r_{0}^{2}}{\delta^{2}} \int_{0}^{\gamma} \int_{0}^{2 \pi} p \sin \theta d \theta d z \\
M_{z^{\prime}}^{(1)}=\omega r_{0}^{2} r_{1}^{2} \mu \int_{0}^{\gamma}\left(\frac{\partial^{2} \widetilde{\psi}^{(1)}}{\partial \xi^{2}} \frac{1}{h^{2}}+\frac{\partial \widetilde{v}^{(1)}}{\partial \xi} \frac{1}{h}\right)_{\xi=0} d \theta d z, \\
N^{(1)}=0 \text { npu } z \in\left(\frac{z_{1}}{r_{0}}, \frac{z_{2}}{r_{0}}\right) .
\end{gathered}
$$

У разі задачі 2:

$$
\begin{gathered}
R_{y^{\prime}}^{(2)}=\frac{\left(r_{1}+l \operatorname{tg} \alpha\right)\left(r_{0}+l \operatorname{tg} \alpha\right)^{3} \mu \omega}{\delta^{2}} \int_{0}^{\gamma} \int_{0}^{2 \pi} p \sin \theta d \theta d z, \\
M_{z^{\prime}}^{(2)}=\omega\left(r_{0}+l \operatorname{tg} \alpha\right)^{2}\left(r_{1}+l \operatorname{ltg} \alpha\right)^{2} . \\
\cdot \mu \int_{0}^{\gamma}\left(\frac{\partial^{2} \tilde{\psi}^{(2)}}{\partial \xi^{2}} \frac{1}{h^{2}}+\frac{\partial \tilde{v}^{(2)}}{\partial \xi} \frac{1}{h}\right)_{\xi=0} d \theta d z, \\
N^{2}=0 \text { npuz } \bar{z}\left(\frac{z_{1}}{r_{0}+l \operatorname{tg} \alpha}, \frac{z_{2}}{r_{0}+l \operatorname{tg} \alpha}\right) .
\end{gathered}
$$

Використовуючи метод суперпозиції для основних робочих характеристик, отримаємо вирази:

$$
\begin{gathered}
R_{y^{\prime}}=R_{y^{\prime}}^{(1)} \theta^{*}+R_{y^{\prime}}^{(2)}\left(1-\theta^{*}\right), \\
M_{z^{\prime}}=M_{z^{\prime}}^{(1)} \theta^{*}+M_{z^{\prime}}^{(2)}\left(1-\theta^{*}\right), \quad \theta^{*} \in[0,1] .
\end{gathered}
$$

Iз знайдених аналітичних виразів для основних робочих характеристик збірного конічного підшипника витікає, що ці характеристики істотно залежать від наступних параметрів: $N^{(1)} \cdot A^{*^{(1)}}, N^{(2)} \cdot A^{*(2)}$, що відповідно харак-теризують безрозмірну швидкість на робочій пористій поверхні збірної циліндрової втулки радіусом $r_{1}$ і радіусом $r_{1}+l \operatorname{tg} \alpha$; $\Omega / \omega$ - які характеризують відносне коливання, що накладається на кутову швидкість обертання вала; $M_{1}^{(1)}, M_{2}^{(1)}$ - обумовлених силою інерції змащувальної рідини; $B^{*(1)}-$ обумовленого нестаціонарною рівняння Дарсі; $\left(\frac{z_{2}}{r_{0}}-\frac{z_{1}}{r_{0}}\right)-$ що характеризує протяжність пористої компоненти збірного конічного підшипника; $\alpha$ - характеризує конусність підшипника.

Результати аналізу (рис. 2) показують наступне: 

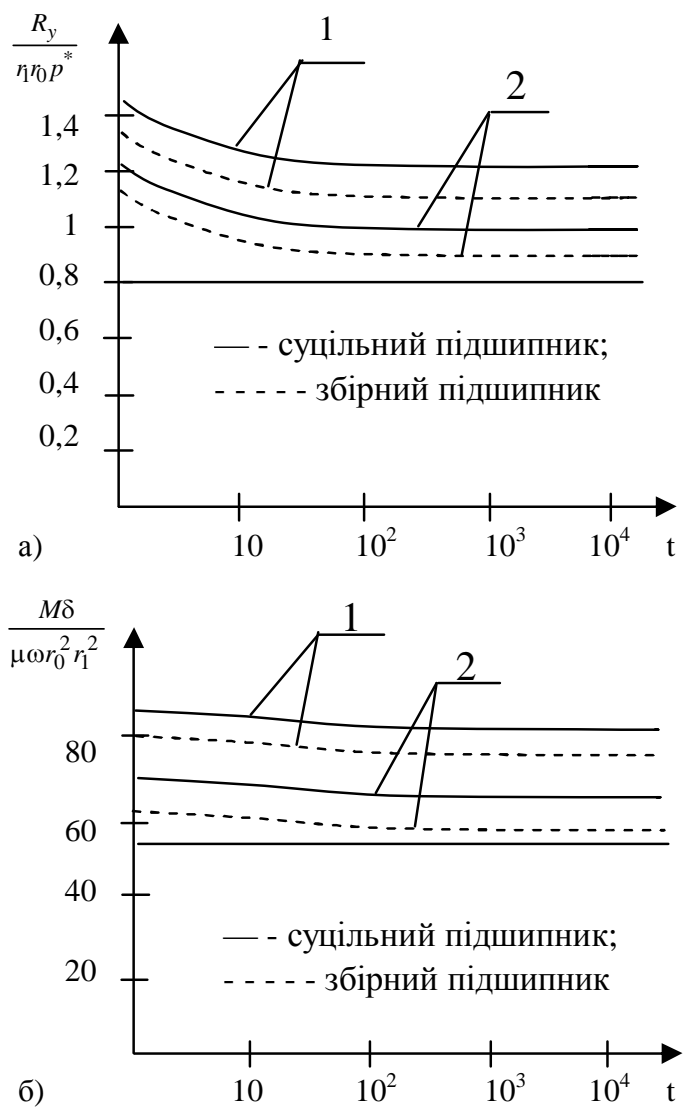

Рис. 2. Залежність безрозмірної несучої здатності (a) i безрозмірного моменту тертя (б) від безрозмірного часу при різних значеннях кута конусності і відносної протяжності пористої складової конічного підшипника, де:

p' - гідродинамічний тиск у змащувальному шарі; $P^{\prime}$ - гідродинамічний тиск у пористому шарі; $e$ ексцентриситет; $r_{0}$ - радіус шпильки; $r_{l}$ - радіус вкладиша (у перетині $z=0) ; r_{2}-r_{l}-$ товщина пористого шару; $r$, $\theta, z^{\prime}$ - циліндрові координати; $\rho$ - густина оливи; $R_{y}^{(1)}$ - проекція головного вектора дії оливи на підшипник; $M_{z}^{(1)}$ - момент сили тертя у разі задачі $1 ; R_{y}^{(2)}, M_{z}^{(2)}-$ момент сили тертя У разі задачі $2 ; v_{r^{\prime}}, v_{\theta}, v_{z^{\prime}}-$ компоненти вектора швидкості; $k$ - проникність; $\mu-$ динамічний коефіцієнт в' язкості.
1. Безрозмірна несуча здатність і безрозмірний момент тертя із збільшенням значення безрозмірного часу прагнуть до значень, що відповідають стаціонарному режиму.

$$
\begin{gathered}
N^{(1)} A^{*(1)}=0,2 ; B^{*(1)}=10 ; \Omega / \omega=0,1 \sin \omega^{*} t ; \\
\omega^{*}=0,2, \eta=0,2 ; A_{0}^{*(1)}=1 ; \theta^{*}=1 / 2 ; \\
1--\alpha=6^{0}, \frac{z_{2}}{r_{0}}-\frac{z_{1}}{r_{0}}=\frac{1}{2} ;---\alpha=6^{0}, \frac{z_{2}}{r_{0}}-\frac{z_{1}}{r_{0}}=\frac{1}{6} ; \\
2--\alpha=3^{0}, \frac{z_{2}}{r_{0}}-\frac{z_{1}}{r_{0}}=\frac{1}{2} ;---\alpha=3^{0}, \frac{z_{2}}{r_{0}}-\frac{z_{1}}{r_{0}}=\frac{1}{6} .
\end{gathered}
$$

2. Найбільш оптимальним (по несучій здатності i моменту тертя) $є$ значення кута конусності, близьке до $60^{\circ}$, і відносна протяжність пористої складової, рівна 1/6.

\section{Висновок}

Запропонована нелінійна математична модель гідродинамічного розрахунку збірного конічного підшипника. Встановлені оптимальні (по несучій здатності і моменту тертя) значення кута конусності і протяжності пористої складової збірного конічного підшипника.

\section{Список літератури}

1. Соломин О.В. Численное определение поля давлений в конических опорах жидкостного трения / O.В. Соломин, А.Ю. Корнеев // Вестник машиностроения. 2005, № 8. - C. 46-50.

2. Коваленко В.Ф. Гравітаиійна течія аномальнов'язких рідин по конічних поверхнях: Автореф. дис... канд. техн. наук: 05.23.16 / Київський національний ун-m будівництва і архітектури. - К., 2001. - 20 c.

3. Ахвердиев К.С. Математическая модель расчета пористого конического подшипника / К.С. Ахвердиев, М.А. Мукутадзе, Б.Е. Копотун // Вестник РГУПС. - № 3. - 2006. - C. 5-16.

4. Методичний посібник з деталей машин та основ конструювання для студентів спеціальності: 7.010104 «Професійне навчання», - Херсон: ХДПУ, 2002. - 120 с.

Надійшла до редакиії 27.08.2009 p.

\title{
МАТЕМАТИЧЕСКОЕ МОДЕЛИРОВАНИЕ ГИДРОДИНАМИЧЕСКОЙ СМАЗКИ СБОРНОГО КОНИЧЕСКОГО ПОДШИПНИКА $З$ ПОРИСТЫМ СЛОЕМ НА ЕГО РАБОЧЕЙ ПОВЕРХНОСТИ
}

\author{
С.И. Задериенко
}

В работе на основе нестачионарных нелинейных уравнений Навье-Стокса для случая «тонкого слоя» и уравнения Дарси с использованием принципа конструктивной суперпозиции разработан метод гидродинамического расчета сборного конического подшипника опорных узлов вооружения и военной техники. Дана оценка влияния угла конусности и протяженности пористой составляющей на основные рабочие характеристики подшипника.

Ключевые слова: вооружение и военная техника, гидродинамическая смазка, сборный подшипник, пористый слой. 


\title{
MATHEMATICAL MODELLING OF HYDRODYNAMIC LUBRICATION OF COLLAPSIBLE TAPERED
} BEARING WITH POROUS LAYER ON ITS FUNCTIONAL SURFACE

\author{
S.I. Zaderiyenko
}

On the basis of navier-stokes non-stationary non-linear equations for cases of «thin layer» and darcy equation using the structural supposition principle the method of hydrodynamic calculation of collapsible tapered bearing reference nodes of armament and military materiel has been developed. the estimate of the taper and length angle of porous component on the basic performance characteristics of the bearing has been made.

Keywords: armament and military materiel, hydrodynamic lubrication, tapered bearing, porous layer.

УДК 621.891:621.316

В.В. Запорожец ${ }^{1}$, В.Н. Стадниченко ${ }^{1}$, О.Н. Трошин ${ }^{2}$, Н.Г. Стадниченко ${ }^{2}$, Р.Н. Джус ${ }^{2}$

${ }^{1}$ Начиональный авиачионный университет, Киев

${ }^{2}$ Харьковский университет Воздушньх Сил им. И. Кожедуба, Харьков

\section{О МЕХАНИЗМАХ ПОДВИЖНОСТИ МЕТАЛЛОКЕРАМИЧЕСКОГО СЛОЯ В ТЕХНОЛОГИЯХ ТРИБОТЕХНИЧЕСКОГО ВОССТАНОВЛЕНИЯ ДЕТАЛЕЙ}

В статье предпринята попытка более подробно описать и раскрыть механизм безызносного трения металлокерамического слоя при использовании технологий триботехнического восстановления. Описана физическая картина диссипаџии внешней энергии при условии подвижности этого слоя, предложена физико-статистическая модель динамики его деформирования.

Ключевье слова: металлокерамический слой, металлокерамическое покрытие, технологии триботехнического восстановления, безызносное трение, диссипаџия внешней энергии, трибовосстанавливаюший состав, эффективный объем взаимодействия.

\section{Вступление}

Наибольший финансовый эффект связанный с прогрессом в области машиностроения, в том числе и в интересах военно-промышленного комплекса, обусловлен снижением затрат на обслуживание и ремонт, которые поглощают весьма значительную и c каждым годом все возрастающую долю национального дохода промышленно развитых стран. Например, в США на ремонт промышленного оборудования в 1966 г. было израсходовано 16 млрд дол., в 1977 г. - свыше 20 млрд дол., в 1990 г. - уже свыше 39 млрд дол., а в 2007 г. более 80 млрд дол. [1]. Исходя из вышеизложенного, следует признать актуальность и перспективность разработки новых и совершенствования существующих технологий в этом направлении.

Анализ последних исследований и публикаций. В настоящее время достаточно широко распространились технологии по восстановлению ресурса механизмов и машин, которые включают способы обработки трущихся поверхностей без их разборки и прекращения эксплуатации - так называемые технологии триботехнического восстановления (ТТВ). Наибольшее распространение получили такие, как «РВC», «Nanoprotec» Россия и «ХАДО» Украина
[1]. Дальнейшим развитием этой технологии является разработка трибовосстанавливающей смеси «Комбат» [2].

Данная технология образования металлокерамического (МК) слоя на поверхностях контакта трибосистем (ТС) включает в себя приготовление восстановительной смеси, ее подачу в зону трения посредством рабочей жидкости (смазочной среды), приработки пары трения. Трибовосстанавливающий состав (ТВС) готовят на основе минеральных веществ и соединений или их смесей, которые содержат оксид кремния в метастабильном состоянии, и катализаторов (табл.).

Таблийа

Состав ТВС «Комбат»

\begin{tabular}{|c|c|c|c|c|c|c|c|c|}
\hline $\mathrm{Al}_{2} \mathrm{O}_{3}$ & $\mathrm{SiO}$ & $\mathrm{Fe}$ & $\mathrm{K}$ & $\mathrm{Ca}$ & $\mathrm{Ti}$ & $\mathrm{Cl}$ & $\mathrm{S}$ & $\mathrm{P}$ \\
\hline 44,5 & 52,7 & 0,96 & 0.52 & 0,11 & 0,39 & 0,04 & 0,02 & 0,04 \\
\hline
\end{tabular}

Изготовление ТВС осуществляют в два этапа. Сначала готовят первую часть упомянутой смеси на основе минеральных веществ и соединений, которые содержат оксид кремния и оксид алюминия в метастабильном состоянии, потом готовят вторую часть смеси на основе катализаторов, в качестве последних используют катализаторы металлических мыл, причем упомянутая первая часть составляет $30 . .45 \%$ масс. ед. от общей массы ТВC, 